This item was submitted to Loughborough's Research Repository by the author.

Items in Figshare are protected by copyright, with all rights reserved, unless otherwise indicated.

\title{
Investigating the effects of control lines on a frequency reconfigurable patch antenna
}

PLEASE CITE THE PUBLISHED VERSION

http://www.lapconf.co.uk/

PUBLISHER

Loughborough University (@ IEEE)

VERSION

VoR (Version of Record)

LICENCE

CC BY-NC-ND 4.0

REPOSITORY RECORD

Yadav, Ajit M., C.J. Panagamuwa, and R.D. Seager. 2019. "Investigating the Effects of Control Lines on a Frequency Reconfigurable Patch Antenna". figshare. https://hdl.handle.net/2134/8099. 
This item was submitted to Loughborough's Institutional Repository (https://dspace.lboro.ac.uk/) by the author and is made available under the following Creative Commons Licence conditions.

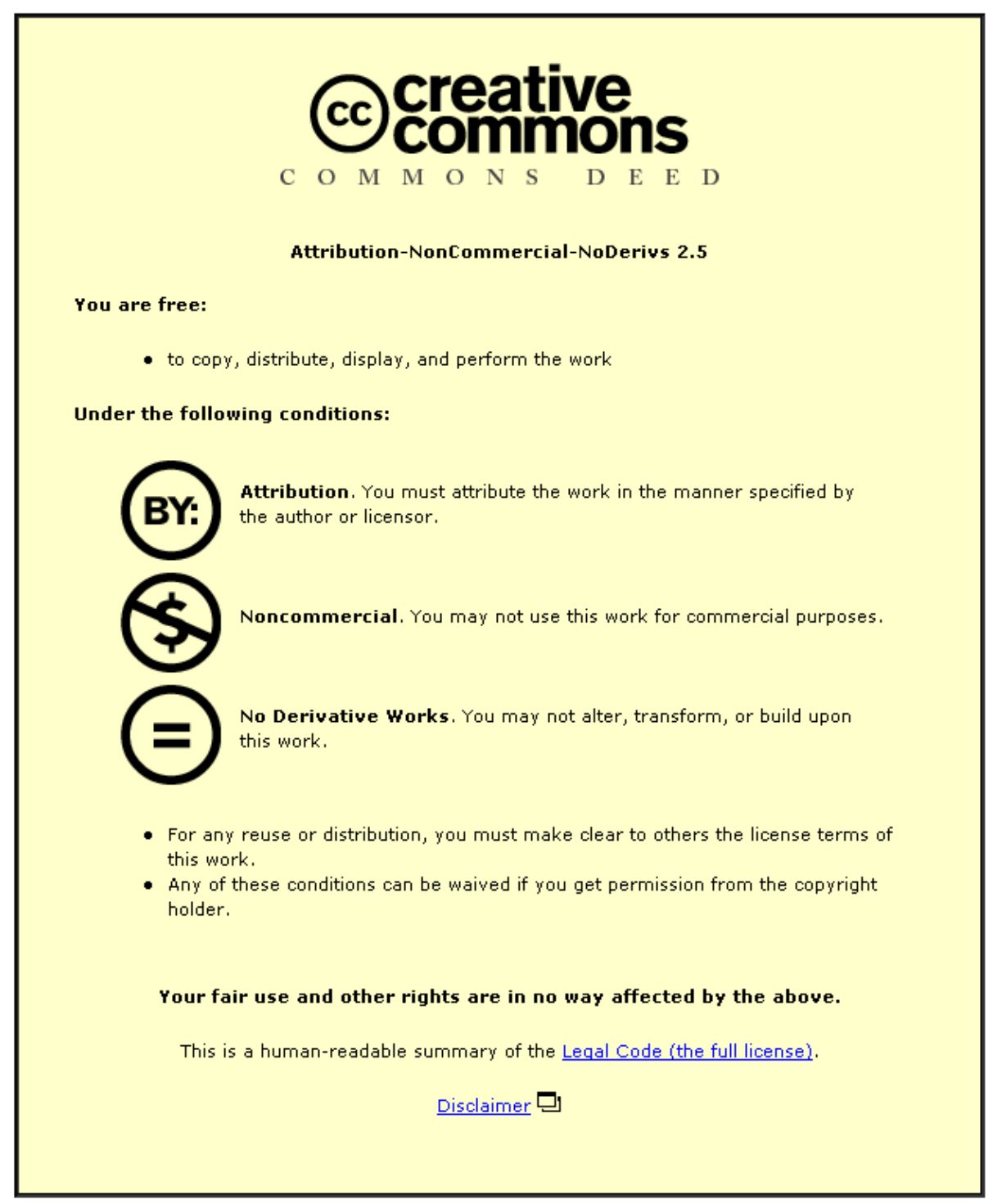

For the full text of this licence, please go to: http://creativecommons.org/licenses/by-nc-nd/2.5/ 


\title{
Investigating the Effects of Control Lines on a Frequency Reconfigurable Patch Antenna
}

\author{
A.M. Yadav ${ }^{\# 1}$, C.J. Panagamuwa ${ }^{\# 2}$, R.D. Seager ${ }^{\# 3}$ \\ \# Department of Electronic and Electrical Engineering, Loughborough University \\ Loughborough, LE11 3TU, United Kingdom \\ ${ }^{1}$ A.M.Yadav2@1boro.ac.uk \\ ${ }^{2}$ C.J.Panagamuwa@lboro.ac.uk \\ ${ }^{3}$ R.D.Seager@lboro.ac.uk
}

\begin{abstract}
The objective of the paper is to investigate the effects of metallic control lines on a frequency reconfigurable patch antenna. The designed antenna resonates at 3 different frequencies in range of 3-4GHz. Simulation and measurement results of return loss with and without control lines are presented. We have also discussed the challenges of implementing the bias lines.
\end{abstract}

Keywords- Reconfigurable antennas, electronic switching, PIN Diode, bias lines.

\section{INTRODUCTION}

With increasing functionalities of current wireless platforms, reconfigurable antennas have become an attractive option for multi-band operations. These antennas are designed to hop over different frequency bands, polarization and radiation patterns dynamically. Reconfiguration using electronic switches such as PIN diodes, Varactor diodes or MEMS has been extensively investigated by many groups [1-3]. Optically controlled antennas are also promising candidates to achieve reconfigurable antennas. It has been successfully demonstrated in dipole, monopoles and patch antennas [4-7].

PIN diodes are controlled by DC bias voltages to behave like an open or short circuits. They offer fast switching speeds, simplicity, more matured technology compared to RF-MEMS or optical switches, good isolation, and low insertion loss. Despite of all these advantages, it has been reported that control lines used to activate these switches may interfere with current distribution on the antenna, de-tune and alter the radiation patterns. They also limit the power that can be handled by antenna. Above $3 \mathrm{GHz}$, the parasitic packaging effects and self-resonance effects of these components become significant [8-12].

Apart from the above claims, the integration of PIN diodes and effects of metallic control lines has not been fully demonstrated in a majority of the published research. Investigators often resort to using copper tape as switches and so completely avoid the issue of routing biasing lines onto the antenna. The aim of this paper is to examine the behaviour of control lines and their effects on reconfigurable antennas performance. We have attempted to model these lines in the simulations in order to reliably predict the antenna operating frequencies of a prototype.

\section{DESCRIPTION}

Fig.1 shows, the rectangular patch antenna designed on a dielectric material with a dielectric constant of 2.36 with thickness of $1.16 \mathrm{~mm}$. The basic design is based on the published paper [6]. The antenna consists of a rectangular patch, switchable slot and a capacitive tab positioned at the top edge of the patch. It is edge-fed using a quarter-wave transformer and $50 \Omega$ transmission line. Dimensions are given in Table I

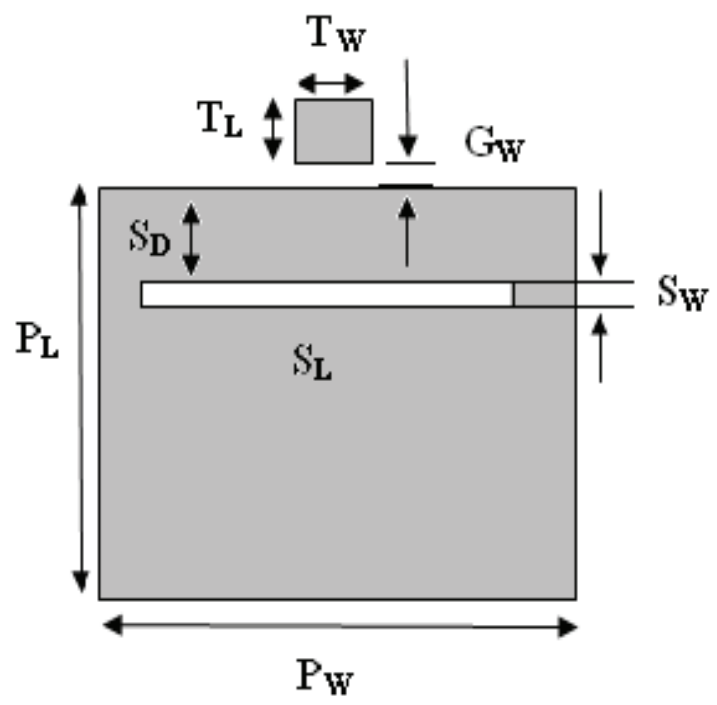

Fig: 1 The Geometry of the Patch antenna

TABLE I.

Dimensions of the Patch Antenna

\begin{tabular}{|l|l|l|l|l|l|l|l|}
\hline $\mathrm{P}_{\mathrm{L}}$ & $\mathrm{P}_{\mathrm{W}}$ & $\mathrm{S}_{\mathrm{L}}$ & $\mathrm{S}_{\mathrm{W}}$ & $\mathrm{S}_{\mathrm{D}}$ & $\mathrm{T}_{\mathrm{L}}$ & $\mathrm{T}_{\mathrm{W}}$ & $\mathrm{G}_{\mathrm{W}}$ \\
\hline 24 & 29 & 17.43 & 0.75 & 4.8 & 2.54 & 3.69 & 0.5 \\
\hline
\end{tabular}


Two PIN diodes as electronic switches are implemented to tune the antenna operating frequency. One diode is placed on the capacitive tab (SW1) and other on the slot (SW2). A thin slit is cut from the slot to accommodate two DC blocking capacitors of $10 \mathrm{pF}$ at the edges and one on the feeding line.

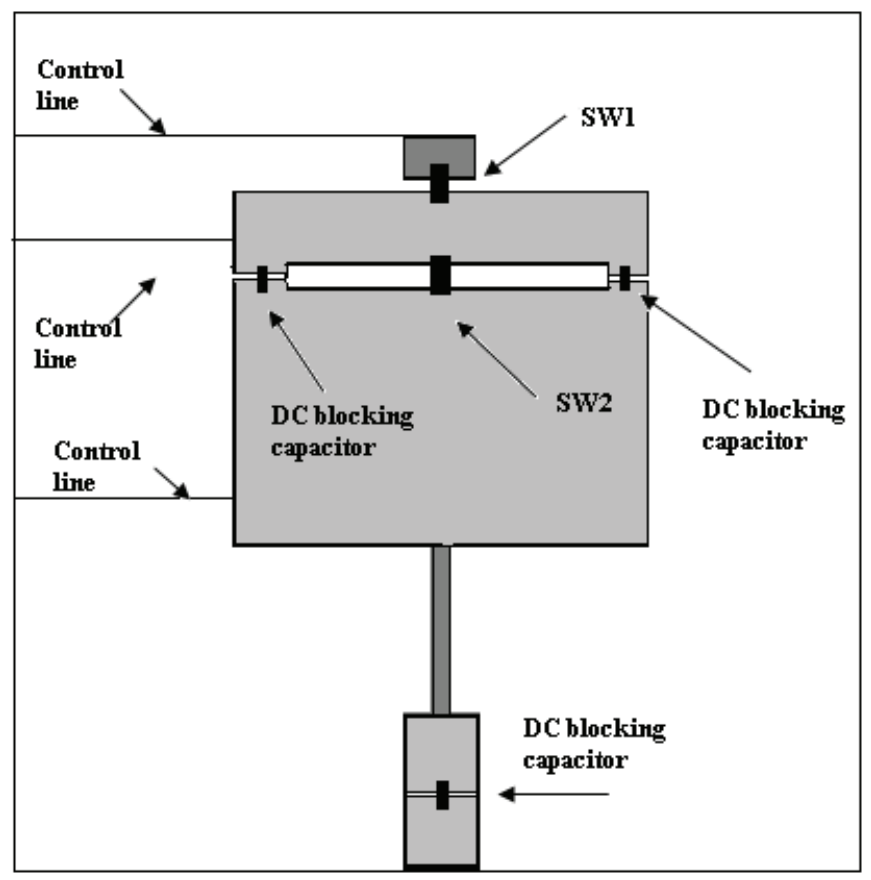

Fig: 2 Patch with switches and blocking capacitors.

The main function of the slot is to disturb the current flow at the surface of the radiating patch. The distance that the current travels gives significant effects to the return loss across the frequency range. When the switch across the capacitive tab (SW1) is ON and switch on the slot (SW2) is OFF, the effective length of the antenna appears to be longer which causes the antenna to operate at the lowest frequency. When the slot switch (SW2) is ON and switch on the capacitive tab (SW1) is OFF, the slot is shorted and currents on the patch travels shorter distance which causes the antenna to operate at the highest frequency. When both the switches are OFF, the capacitive tab is disconnected, but due to the slot, currents on the patch flow around the slot making it look electrically longer and thus decreasing the operating frequency. In this case antenna operates at middle frequency.

\section{SIMULATIONS}

In order to study the antenna behaviour, it is important to model the antenna with all the critical components which can influence the overall antenna performance. Analysis is carried out in CST Microwave Studio ${ }^{\circledR}$ where PIN diodes are modelled as small capacitors in the OFF state and resistors in the $\mathrm{ON}$ state. The value of the capacitance is $0.3 \mathrm{pF}$ and resistance is $1.2 \Omega$ as provided in the data sheet of the PIN diode (Skyworks SMP 1340-079LF).
DC blocking capacitors are modelled as lumped elements and appropriate metallic biasing lines are included to refine the final antenna design. Extensive Parametric studies were carried out to optimise the locations of bias lines so that their impact on the antenna performance was minimised. Furthermore, the width of the biasing lines were reduced to the smallest printable dimension $(0.2 \mathrm{~mm})$ so that their impedances were increased. Two cases are presented which includes the antenna with and without biasing lines.

Case 1: Implementation with PIN diodes and DC blocking capacitors

Case 2. Implementation with PIN diodes, DC blocking capacitors and metallic biasing lines.

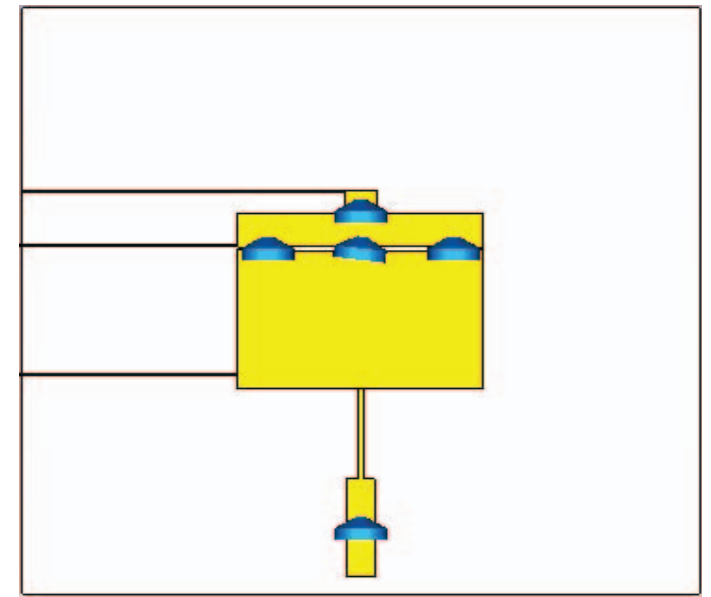

Fig: 3 Implementation of control lines in CST Microwave studio ${ }^{\circledR}$

A. Simulation results.

Case: 1

When switch 1 is ON and Switch 2 is OFF, the antenna operates at $3.28 \mathrm{GHz}$, When Switch 1 is OFF and Switch $2 \mathrm{ON}$, the antenna operates at highest frequency i.e. $3.64 \mathrm{GHz}$ and when both switches are OFF, it operates at $3.4 \mathrm{GHz}$. The simulated S11 for each state is shown below.

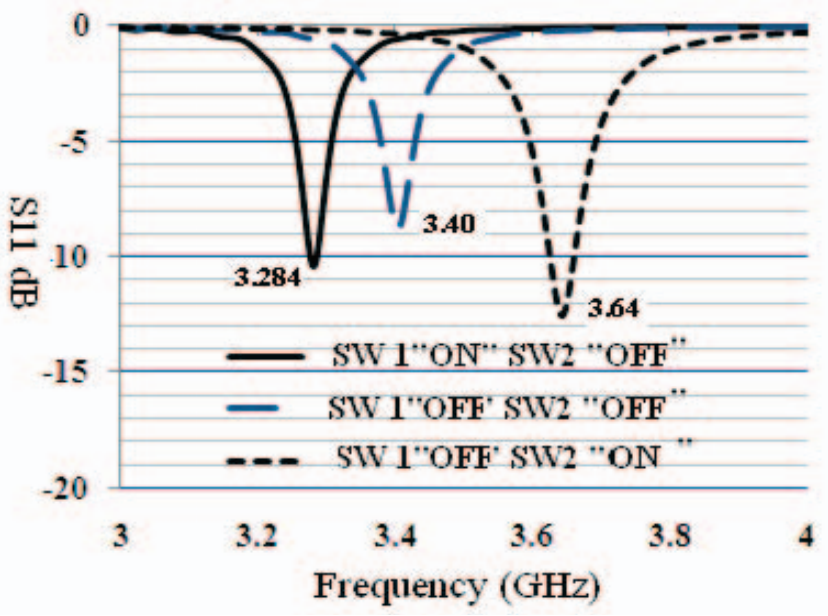

Fig: 4 Simulation result with case 1 
Case: 2

When switch 1 is ON and Switch 2 is OFF, the antenna operates at $3.1538 \mathrm{GHz}$, When Switch 1 is OFF and Switch 2 $\mathrm{ON}$, the antenna operates at highest frequency i.e. $3.64 \mathrm{GHz}$ and when both switches are OFF, it operates at $3.4 \mathrm{GHz}$. The simulated S11 for each state is shown in fig.5

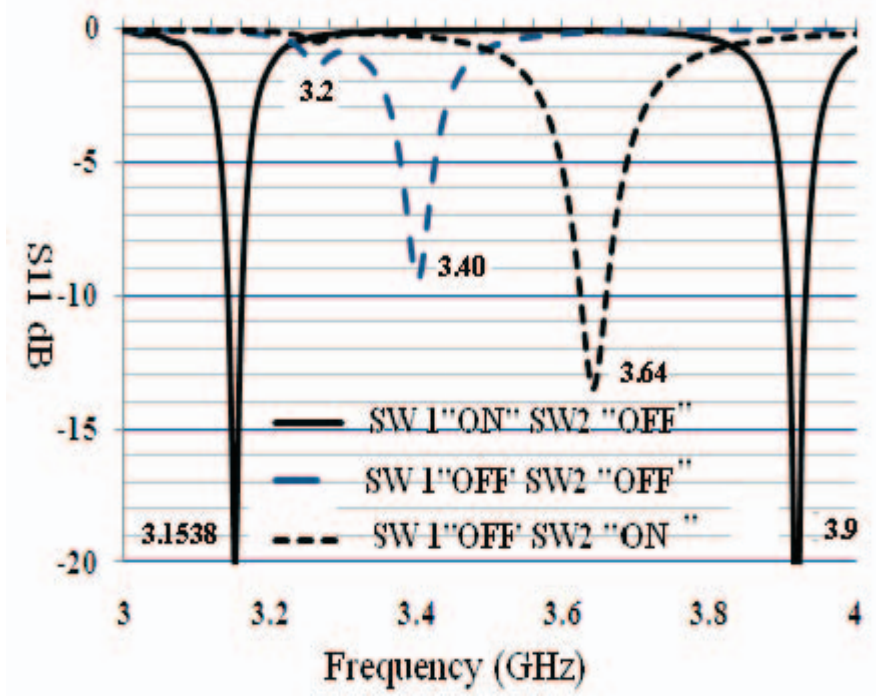

Fig: 5 Simulation result with case 2

\section{COMPARISION}

In this section, we compare the simulation result of the return losses with case 1 and case $2 \mathrm{We}$ observe that control lines alter the frequency tuning characteristics as shown in fig 5 . This is evident from the fact that there is a $3.96 \%$ frequency shift in the simulation result implementing control lines when the capacitive switch (SW1) is ON and has a prominent second resonance around $3.9 \mathrm{GHz}$.

\section{MEASUREMENT}

The prototype based on the simulation model has been fabricated and measured.

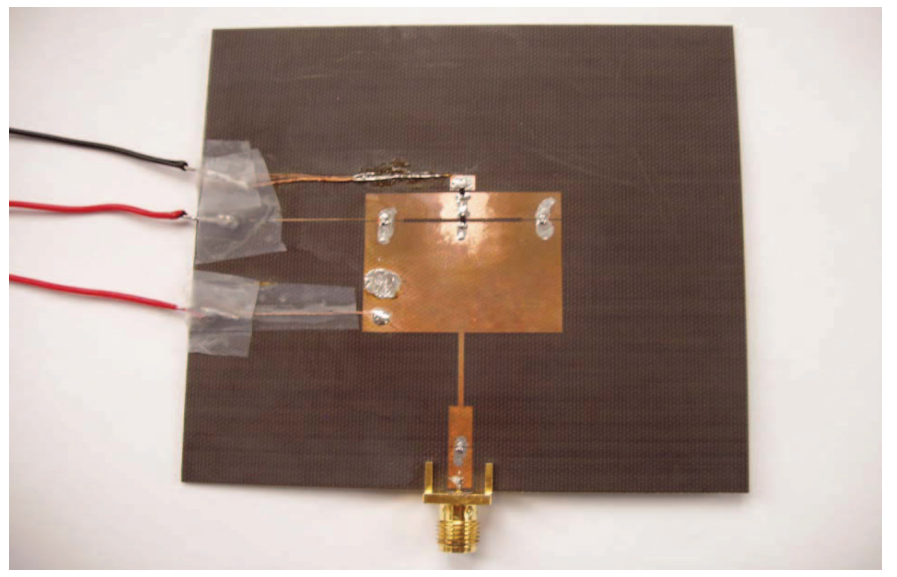

Fig: 6 Prototype of the patch antenna
Return loss measurement was performed using Anritsu Vector Network analyser 37397D and diodes were biased using a DC power supply with $10 \mathrm{~mA}$ current and forward voltage of $0.85 \mathrm{~V}$.

\section{MEASUREMENT RESULTS}

When switch 1 is $\mathrm{ON}$ and Switch 2 is OFF, the antenna operates at $3.06 \mathrm{GHz}$, When Switch 1 is OFF and Switch 2 ON, the antenna operates at highest frequency i.e. $3.59 \mathrm{GHz}$ and when both switches are OFF, it operates at $3.03 \mathrm{GHz}$.

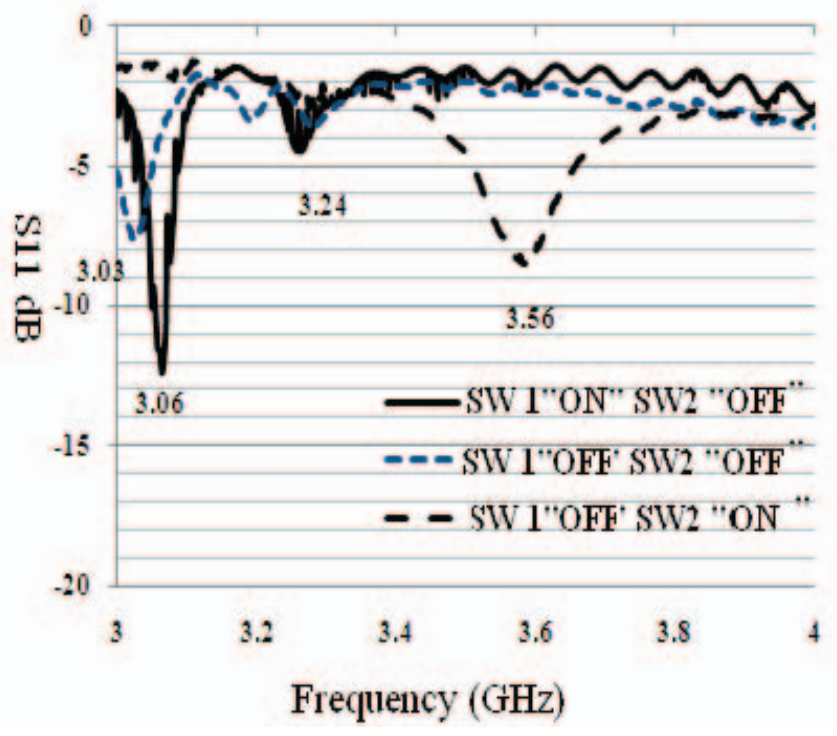

Fig: 7 Measurement result with case 2

\section{DISCUSSION}

Table II

Comparison of simulated and measured antenna operating frequencies

\begin{tabular}{|l|l|l|}
\hline $\begin{array}{l}\text { Switch } \\
\text { Condition }\end{array}$ & Simulation & Measurement \\
\hline $\begin{array}{l}\text { SW1ON, } \\
\text { SW2 OFF }\end{array}$ & $3.15 \mathrm{GHz}$ & $3.06 \mathrm{GHz}$ \\
\hline $\begin{array}{l}\text { Both SW } \\
\text { OFF }\end{array}$ & $3.40 \mathrm{GHz}$ & $3.03 \mathrm{GHz}$ \\
\hline $\begin{array}{l}\text { SW1OFF, } \\
\text { SW2 ON }\end{array}$ & $3.64 \mathrm{GHz}$ & $3.59 \mathrm{GHz}$ \\
\hline
\end{tabular}

The table shows that there is reasonable agreement between simulation and measurement in two of the operational states. However, in the case where both switches are OFF, there is a considerable difference in the operational frequency between simulation and measurement $(3.4 \mathrm{GHz}$ compared to $3.03 \mathrm{GHz})$. It appears that the soldering of off-board biasing lines to connect the DC power supplies to the antenna have detuned the antenna operating frequencies. It was observed that the 
operating frequencies were very sensitive to the location of the dangling biasing wires.

\section{CONCLUSIONS}

This work presents the simulation and measurement results of a study on the effects of control lines with electronically tuned antennas. Although care was taken to optimise the location of the biasing lines in the simulations, the measurement results show that it is difficult to predict the full effects of the biasing lines. Any movement to the biasing lines detune the antenna and so in a practical application, all wires must be secured. Simulating models with biasing lines may add to the complexity and processing time without any real benefits. For higher frequencies and for complex antennas with more switches, the effects of control lines may have a greater influence on antenna operating frequency and radiation characteristics.

\section{REFERENCES}

[1] C.Luxey, L.Dussopt, J-L.Sonn and J.M.Laheure, "Dual frequency operation of CPW-feed antenna controlled by pin diodes", Electronics Letters, vol.36.no.1, pp 2-3, 2000.

[2] E. Brown ,"RF-MEMS switches for reconfigurable integrated circuits", IEEE Transactions on Microwave theory and techniques, vol. 46, no.11 pt 2, pp. 1868-1880, 1998.

[3] P.Bhartia, I.J.Bahl, " Frequency agile microstrip antennas", Microwave Journal, vol.25, pp-67-70, 1982.

[4] J.L Freeman, B.J.Lamberty, G.S Andrews, " Optoelectronically reconfigurable monopole antennas", Electronic Letters, vol.28, no.16, pp-1502-1503, 1992.
[5] C.J Panagamuwa, A.Chauraya and J.C Vardaxoglou, " Frequency and beam reconfigurable antenna using photoconducting switches," IEEE Transactions on Antenna and Propagation, vol.54, no.2, pp 449-54, Feb.2006.

[6] R.N.Lavallee and B.A.Lail, "Optically-controlled reconfigurable microstrip patch antenna," IEEE AP-S International symposium 2008 , vol-2, pp.01-04, 2008.

[7] D.Draskovic, C.Panagamuwa, J.C.Vardaxoglou, D.Budmir, "Frequency reconfigurable RF circuits using photoconductive", International Journal of RF and Microwave Computer-Aided Engineering, vol. 20, no.1, pp.15-20,2010.

[8] Y.Tawk, Alex R.Albrecht, S.Hemmady, Gunny Balkrishnan and Christos G. Christodoulou, " Optically pumped Frequency Reconfigurable Antenna Design", IEEE Antennas and Wireless Propagation, vol.9, pp- 290-283, 2010.

[9] Limin Huang and Michael P.De lisio , " An Electronically switchable leaky wave antenna", IEEE Transactions on Antennas and Propogation, Vol.48, no.11, 2000.

[10] Carla Mederios, Ana Castela, Jorge Costa and Carlos Fernandes "Evaluation of Modelling Accuracy of Reconfigurable Patch Antennas", Proc Conf. on Telecommunications - ConfTele, Peniche, Portugal, Vol. 1, pp. 13 - 16, 2007.

[11] Songnan Yang, Chunna Zhang, Helen K.Pan, Aly E.Fathy and Vijay Nair, " Frequency reconfigurable antennas for multiradio wireless platforms", IEEE Microwave Magzine,pp-66-83, Feburary 2009.

[12] J.Liang and H.Y.D.Yang," Varactor loaded tunable printed PIFA", Progress In Electromagnetics Research B, vol.15, pp-113-331, 2009. 